\title{
Using a Commercial Optimisation Tool for Fine Tuning of Parameters of an Eutrophication Model
}

\author{
Albrecht Gnauck ${ }^{1}$, Bernhard Luther ${ }^{1}$, and Wilfried Krug ${ }^{2}$ \\ ${ }^{1}$ Brandenburg University of Technology at Cottbus, Dept. of Ecosystems and Environmental \\ Informatics, Konrad-Wachsmann-Allee 1, D-03046 Cottbus, Germany \\ ${ }^{2}$ DUALIS -IT Solutions GmbH, Tiergartenstraße 32, D-01219 Dresden, Germany \\ \{Albrecht.gnauck, luther\}atu-cottbus.de, wkrug@dualis-it.de
}

\begin{abstract}
Simulation models are well-known informatic tools to manage environmental knowledge. Current approaches to ecosystems modelling are theoretically based on information theory, thermodynamics, topology, or systems theory. Water quality models are used for managing eutrophication problems. In the past, the Cottbus Eutrophication Simulator (CEUS) has been designed on the base of MATLAB and SIMULINK, which enables an user to couple the simulator with different software tools. To quantify these relations differential equations, some site constants and model specific parameters have to be specified. The fine tuning of parameters of an ecological model can be considered from the perspective of a suitable optimization procedure. Especially the commercial optimization software ISSOP realised different optimization algorithms which are traced back to one standard form of discrete optimization. In the paper, results of parameter optimisation will be presented for important water quality indicators. The results of parameter fine tuning and possibilities of parameter optimisation are discussed.
\end{abstract}

Keywords: Optimisation, water quality modelling, eutrophication, parameter estimation.

\section{Introduction}

Modern environmental management decisions are based on mathematical models of ecosystems or ecological processes. To get suitable simulation results for management purposes the process of setting up of parameter values and initial conditions is of high importance. Management options for eutrophication control will be obtained by scenario analyses with changing parameter values [5].

The problem of parameter optimisation can be described related to a models quality and accuracy. Under the prerequisite of well-founded initial parameter settings a higher accuracy can be reached with the help of iterative optimisation. The optimisation procedures refer to goal functions including the output variables of the model. The term of parametrisation in ecological modelling denotes the determination of quantitative values of parameters. Three different approaches can be taken: 
- A preliminary estimate is obtainable from laboratory and field observations of processes and effects by means of correlation analysis or by parameter estimation techniques.

- Combinations of parameters in keeping with a modelled situation may be obtained by means of estimation from parameter optimisation techniques.

- Estimates of parameter importance of a simulation model may be obtained by sensitivity analysis.

The goal of sensitivity analysis is to determine how sensitive the model is to changes of parameter values, which is the basis for model validation and parameter estimation. Investigations of parameter changes are carried out for an eutrophication model of a lowland river basin.

\section{The Optimisation Tool ISSOP}

Krug [3] developed a software tool ISSOP to support manufacturing, organisational and logistic processes. It includes an optimisation interface of MATLAB models. The $I S S O P$ architecture of discrete optimisation methods used is shown in fig. 1.

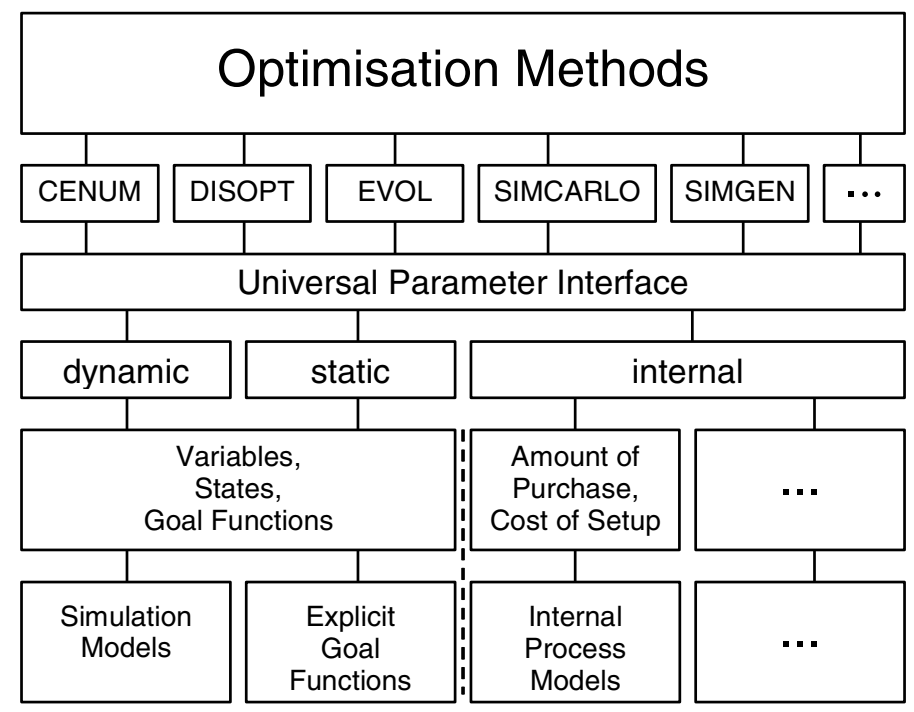

Fig. 1. The ISSOP optimisation architecture

The dialogue between external and internal models and optimisation methods is realised by a universal parameter interface. Following optimisation methods are included: CENUM - component wise enumeration, DISOPT - a quasi-gradient method, EVOL - an evolutionary optimisation strategy, SIMCARLO - optimisation by Monte Carlo method, SIMGEN - optimisation by a genetic algorithm. Other optimisation procedures can be added. Before starting an optimisation run each simulation problem 
is automatically transformed into the standard problem of optimisation. On the lowest level of this architecture simulation models, goal functions and internal process models are given explicitly. External static and dynamic simulation models can be implemented without any restriction. Convexity of goal functions is not necessary.

\section{Parameter Optimisation and Sensitivity}

The parameter sensitivity according to the output variables gives information how to select and weight the parameters and on which range and accuracy they have to be treated (fig. 2).

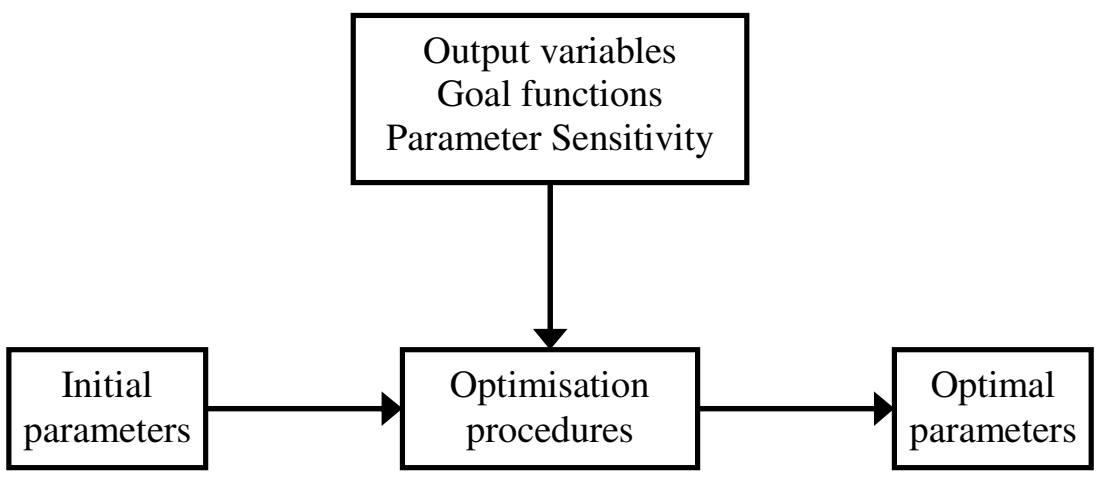

Fig. 2. From initial parameter settings to optimal parameter settings

Three classical approaches to sensitivity analysis can be distinguished:

1. Sensitivity to major parameter changes (The values of some parameters are arbitrarily changed within the expected limits of their validity, and the response of system investigated).

2. Experimental sensitivity analysis (The parameter values $\mathrm{p}_{\mathrm{i}}$ are changed by a finite amount $\Delta \mathrm{p}$, the model rerun and model outputs for nominal and changed parameter vectors abstracted. The result depends on $\Delta \mathrm{p}$ ).

3. Analytical sensitivity analysis (Sensitivity functions are calculated representing partial derivatives of state variables $u_{j}$ to parameters: $S\left(p_{i}\right)=\partial u_{j} / \partial p_{i}$. This differential method of sensitivity analysis is based on linearisation around the nominal solution by numerical or graphical procedures). This procedure is not covered within this paper.

Estimating sensitivity to external parameters, those connected with driving variables or site constants, a picture is getting how a given freshwater ecosystem would behave under different conditions. One particular problem is the sensitivity to sampling intervals or kinds of approximation of driving variables. For internal parameters, those characterising state variables, the goal is to determine the importance of parameters for the approximation of the model to reality. Attention has to be devoted mainly to those parameters, to which the model is most sensitive [4]. 


\section{Results and Discussion}

To investigate parameter optimisation and sensitivity a MATLAB based stationary 1D eutrophication model for shallow water bodies [2] was coupled with the commercial optimisation tool ISSOP [3].

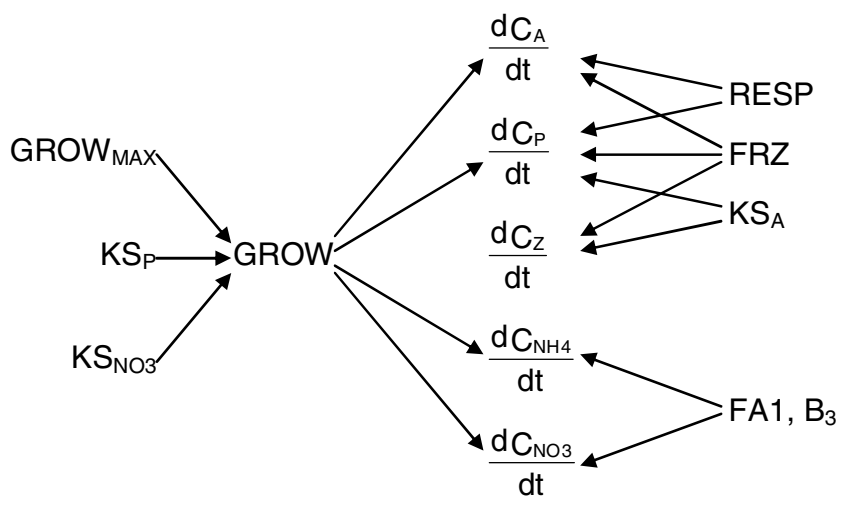

Fig. 3. Direct and indirect relations between model parameters and model variables

Concerning the eutrophication process in figure 3 an overview is presented on direct relationships of important model parameters to model variables. The parameters themselves can be assigned to essential processes in the water body and in the sediment.

The overall growth rate of phytoplankton mainly is determined by the production of algae biomass and the half saturation constants $\mathrm{KS}_{\mathrm{P}}$ (of phosphorus) and $\mathrm{KS}_{\mathrm{NO} 3}$ (of nitrate). It is restricted by an upper bound $\mathrm{GROW}_{\mathrm{MAX}}$ for the nutrient uptake of the phytoplankton. So the constants $\mathrm{GROW}_{\mathrm{MAX}}, \mathrm{KS}_{\mathrm{P}}$ and $\mathrm{KS}_{\mathrm{NO} 3}$ directly affect the phytoplankton concentration and the concentration of the nutrients nitrogen and phosphorus. The nitrogen fraction of algae biomass FA1 and the ammonification rate $\mathrm{B}_{3}$ directly affect the nitrogen compounds ammonium and nitrate. The half saturation constant $\mathrm{KS}_{\mathrm{A}}$ in the balance equation of zooplankton affect zooplankton and phosphorus. The filtration rate FRZ of zooplankton has a direct influence on zooplankton only, and the respiration rate RESP of phytoplankton connects phytoplankton and phosphorus.

For the eight parameters $\mathrm{GROW}_{\mathrm{MAX}}, \mathrm{KS}_{\mathrm{P}}, \mathrm{KS}_{\mathrm{NO} 3}, \mathrm{KS}_{\mathrm{A}}, \mathrm{FRZ}, \mathrm{FA} 1, \mathrm{~B}_{3}$ and RESP initial values $\left(\mathrm{p}^{*}\right)$ are given (table 1$)$. On the base of these values any parameter $\mathrm{p}$ has been varied in the interval $\Delta \mathrm{p}$. According to these parameters a ranking of the variables $\mathrm{x}=\left\{\mathrm{CHA}, \mathrm{o}-\mathrm{PO}_{4}-\mathrm{P}, \mathrm{NH}_{4}-\mathrm{N}, \mathrm{NO}_{3}-\mathrm{N}\right\}$ is presented by means of a Hasse diagram [1] in fig. 4 regarding the global differences

$$
\widetilde{\Delta} \mathrm{x}=\max _{\mathrm{p}, \mathrm{t}}|\Delta \mathrm{x}|=\max _{\mathrm{p}, \mathrm{t}}\left|\Delta \mathrm{x}_{\mathrm{p}}(\mathrm{t})\right|=\max _{\mathrm{p}, \mathrm{t}}\left|\mathrm{x}_{\mathrm{p}}(\mathrm{t})-\mathrm{x}_{\mathrm{p}^{*}}(\mathrm{t})\right| .
$$


Table 1. Reference values and ranges of the eight parameters

\begin{tabular}{|l|c|c|c|}
\hline \multicolumn{1}{|c|}{ Parameter $\mathbf{p}$} & Reference value $\mathbf{p}^{*}$ & $\begin{array}{c}\text { Lower bound } \\
\mathbf{p}_{\text {lower }}=\mathbf{1 0 \%} \cdot \mathbf{p}^{*}\end{array}$ & $\begin{array}{c}\text { Upper bound } \\
\mathbf{p}_{\text {upper }} \mathbf{= 2 0 0 \%} \cdot \mathbf{p}^{*}\end{array}$ \\
\hline GROWMAX & 5 & 0.5 & 10 \\
\hline KSP & 30 & 3 & 60 \\
\hline KSNO3 & 0.1 & 0.01 & 0.2 \\
\hline KSA & 0.06 & 0.006 & 0.12 \\
\hline FRZ & 0.1 & 0.01 & 0.2 \\
\hline FA1 & 50 & 5 & 100 \\
\hline B3 & 0.02 & 0.002 & 0.04 \\
\hline RESP & $1.4 \cdot 10^{-5}$ & $1.4 \cdot 10^{-6}$ & $2.8 \cdot 10^{-5}$ \\
\hline
\end{tabular}

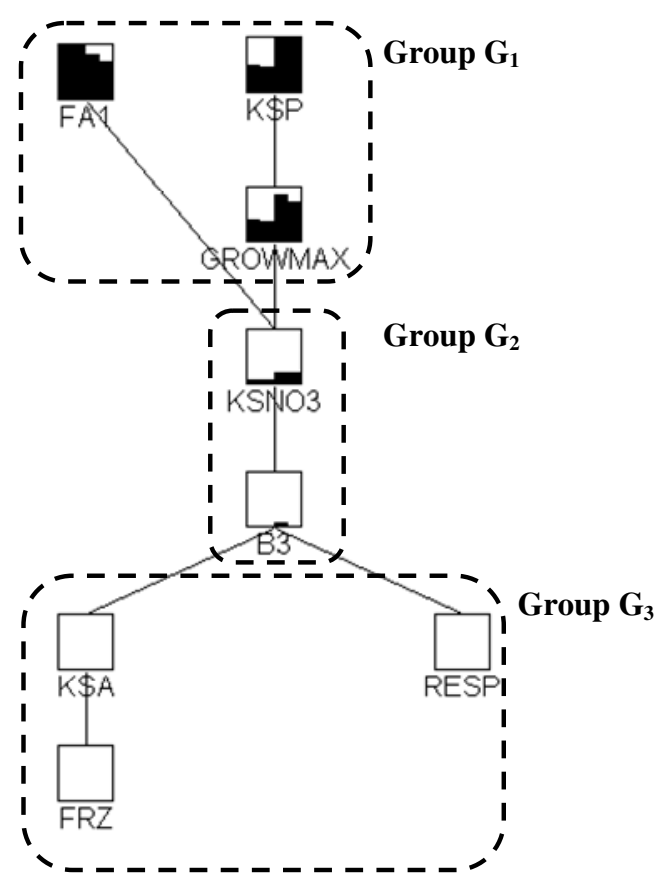

Fig. 4. Hasse diagram of the variables $\mathrm{CHA}, \mathrm{o}-\mathrm{PO}_{4}-\mathrm{P}, \mathrm{NH}_{4}-\mathrm{N}, \mathrm{NO}_{3}-\mathrm{N}$

It is noticeable that the four parameters $\mathrm{GROW}_{\mathrm{MAX}}, \mathrm{FA} 1, \mathrm{KS}_{\mathrm{P}}$, and $\mathrm{KS}_{\mathrm{NO} 3}$ that directly affect the algae growth form the upper half of all rankings. The lower half is formed by the filtration rate of zooplankton, the respiration rate of phytoplankton and the parameters $\mathrm{B}_{3}$ (ammonification rate) and $\mathrm{KS}_{\mathrm{A}}$ (half saturation constant in the balance equation of zooplankton). The two latter mentioned can be seen as parameters of sea-internal driving forces. 

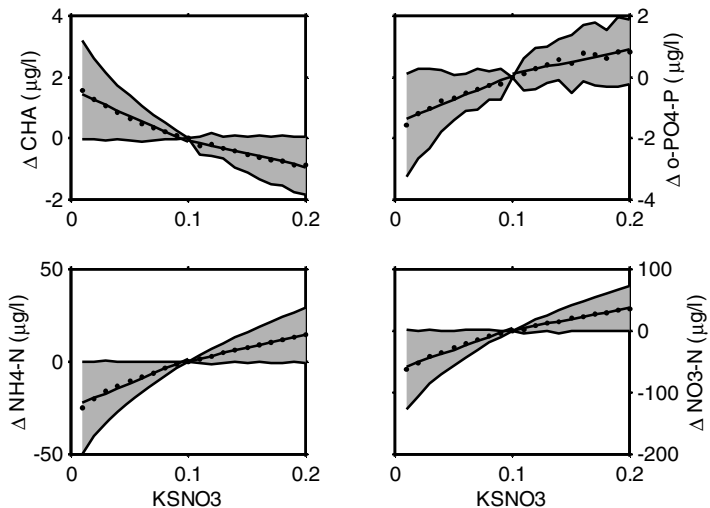

Fig. 5. Sensitivity of the variables $\mathrm{CHA}$, o- $\mathrm{PO}_{4}-\mathrm{P}, \mathrm{NH}_{4}-\mathrm{N}$ and $\mathrm{NO}_{3}-\mathrm{N}$ to $\mathrm{KS}_{\mathrm{NO} 3}$
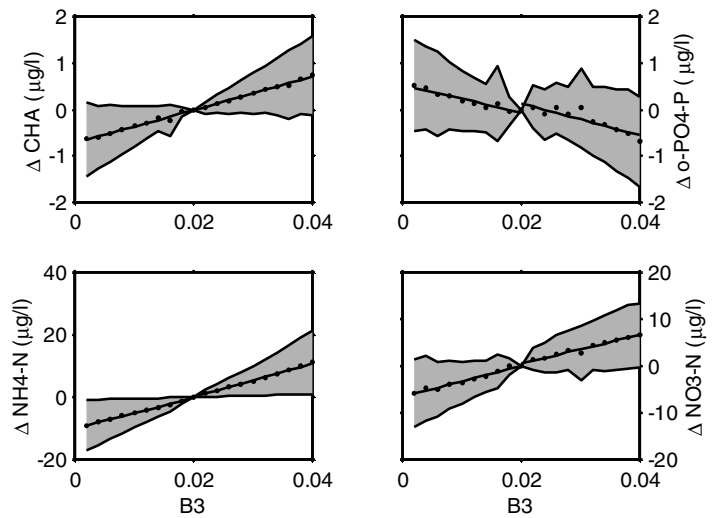

Fig. 6. Sensitivity of the variables $\mathrm{CHA}$, o- $\mathrm{PO}_{4}-\mathrm{P}, \mathrm{NH}_{4}-\mathrm{N}$ and $\mathrm{NO}_{3}-\mathrm{N}$ to $\mathrm{B}_{3}$

More precisely all of the four variables show a partition of the parameter set into three groups:

- Group $\mathrm{G}_{1}=\left\{\mathrm{GROW}_{\mathrm{MAX}}, \mathrm{FA} 1, \mathrm{KS}_{\mathrm{P}}\right\}$ highest sensitivity

- Group $\mathrm{G}_{2}=\left\{\mathrm{KS}_{\mathrm{NO} 3}, \mathrm{~B}_{3}\right\} \quad$ mean sensitivity

- Group $\mathrm{G}_{3}=\left\{\mathrm{KS}_{\mathrm{A}}\right.$, FRZ, RESP $\} \quad$ lowest sensitivity

Figure 5 shows the sensitivity of the variables $\mathrm{CHA}, \mathrm{o}-\mathrm{PO}_{4}-\mathrm{P}, \mathrm{NH}_{4}-\mathrm{N}$ and $\mathrm{NO}_{3}-\mathrm{N}$ according to parameter $\mathrm{KS}_{\mathrm{NO} 3}$, figure 6 shows the results for parameter $\mathrm{B}_{3}$.

\section{Conclusions}

Investigations of parameter sensitivity are essential tasks of the modelling procedure. Especially for complex systems like freshwater ecosystems these investigations are necessary to mark the parameter range of validity for environmental management 
decisions. The output of the eutrophication simulator investigated is most sensitive for parameters characterising phytoplankton growth and dynamics. A second level of sensitivity is given by parameters describing nutrient cycles within the water body. In opposite of that, the influence of zooplankton to phytoplankton was found very stiff.

\section{References}

1. Brüggemann, R., Carlsen, L.: Partial Order in Environmental Sciences and Chemistry. Springer, Berlin (2006)

2. Gnauck, A., Heinrich, R., Luther, B.: Water Quality Management of a Sub-Watershed of the Elbe River. In: Pillmann, W., Tochtermann, K. (eds.) Environmental Communication in the Information Society, Vienna. Internat. Soc. Environm. Protect., pp. 524-531 (2002)

3. Krug, W.: Modelling, Simulation and Optimisation for Manufacturing, Organisational and Logistical Processes. SCS Europe Publishing House, Delft (2002)

4. Luther, B., Gnauck, A.: Parameter Sensitivity of an Eutrophication Model. In: Wittman, J., Flechsig, M. (eds.) 2009: Simulation in Umwelt- und Geowissenschaften, Workshop Potsdam 2009, pp. 125-133. Shaker, Aachen (2009)

5. Straškraba, M., Gnauck, A.: Freshwater Ecosystems - Modelling and Simulation. Elsevier, Amsterdam (1985) 